\title{
Percutaneous transluminal coronary angioplasty in patients 70 years of age or older: 12 years' experience
}

\author{
Kim H Tan, Neil Sulke, Nick Taub, Sheila Karani, Edgar Sowton*
}

\begin{abstract}
Objective-To evaluate the short and long term results of coronary angioplasty in patients aged 70 years and older and identify the determinants of long-term survival.

Design-A retrospective analysis of clinical, angiographic, and procedure related variables on a consecutive series of patients.

Patients-163 patients aged 70 years and older (mean (range) age 73 (70-83) years; $63 \%$ men) who underwent a first coronary angioplasty procedure between 1981 and 1993.
\end{abstract}

Results-Procedural success was achieved in $82 \%$ of patients. Four patients (2\%) died, three (2\%) had a myocardial infarction, and five (3\%) underwent emergency coronary artery bypass surgery. Complete follow up data were available for all patients (median (range) 35 (2-146) months). During the follow up period 16 patients $(10 \%)$ died, two (1\%) suffered non-fatal myocardial infarction, and $12(7 \%)$ underwent elective coronary artery bypass surgery. A second angioplasty procedure was performed in 24 patients (15\%). The cumulative probability of survival was $90.7 \%$ at 1 year and $83.4 \%$ at 5 years. Survival free from myocardial infarction, bypass surgery, and repeat angioplasty at 1 and 5 years was $68 \cdot 2 \%$ and $56 \cdot 0 \%$, respectively. Proportional hazards regression analyses identified incomplete revascularisation as the only independent predictor of poorer overall survival $(P=0.04)$ and event free survival (P<0.001). At census, of the 143 survivors, $75(52 \%)$ were asymptomatic, $58(41 \%)$ had mild angina, and only $10(7 \%)$ complained of grade III or IV angina. Some 112 patients $(78 \%)$ improved by at least two angina grades.

Conclusion-Coronary angioplasty can be performed safely in the elderly and provides good symptomatic relief and favourable long-term outcome. Complete revascularisation may not be necessary if the primary goal is to achieve symptomatic relief, but incomplete revascularisation is associated with poorer long-term survival.

(Br Heart f 1995;74:310-317)
Keywords: percutaneous transluminal coronary angioplasty; coronary artery disease; septuagenarian

Since the proportion of elderly patients suffering from symptomatic coronary artery disease is increasing, ${ }^{1}$ the efficacy of the various forms of treatment modality needs to be constantly evaluated in these patients. Although elderly patients have more extensive atherosclerotic coronary artery disease, most clinicians have adopted a conservative approach towards their management, usually with medications and modification of their activities. This is, in part, attributed to the increased perioperative morbidity and mortality, longer duration of hospitalisation, and less favourable long-term outcome reported in most coronary surgery studies in patients with advanced age compared with that of younger patients with comparable disease. ${ }^{2-4}$ Medical treatment, however, is often ineffective and poorly tolerated in the elderly, and side effects are common. ${ }^{5}$ Furthermore, the limitation of physical activity imposed on these patients to provide symptomatic relief often becomes intolerable.

Percutaneous transluminal coronary angioplasty, by virtue of being less invasive, offers an attractive alternative mode of myocardial revascularisation in these patients. Elderly patients, however, have a higher incidence of impaired left ventricular function and multivessel coronary artery disease, which increases the risk associated with balloon angioplasty. ${ }^{67}$ In addition, coronary lesions in elderly patients tend to be diffuse and calcified, and their vessels are more rigid and tortuous. ${ }^{89}$ This may increase the technical difficulties of angioplasty, and adversely affect the outcome of this procedure.

Previous reports on the acute and longterm results of coronary angioplasty in this subset of patients have shown conflicting results. ${ }^{10-12}$ This study describes the acute and long-term results of coronary angioplasty in patients aged 70 years and older who were treated at our institution over a 12-year period.

\section{Patients and methods}

PATIENTS

Between 1981 and 1993, 163 patients aged 70 years or older underwent their first percutaneous transluminal coronary balloon 
angioplasty at our institution. There were no other exclusion criteria.

The mean (SD) (range) age was $73(3)$ (70-83) years and $102(63 \%)$ were men (table 1). A previous myocardial infarction had occurred in 74 patients $(45 \%)$ resulting in left ventricular dysfunction (ejection fraction < $45 \%$ assessed by contrast ventriculography) in 66 patients $(40 \%)$. Twenty eight patients $(17 \%)$ had previous coronary artery bypass grafting. Coronary angioplasty was performed as an emergency for unstable or post-infarction angina in 27 patients $(17 \%)$. Before intervention, 117 patients (72\%) suffered grade III or IV angina assessed by the Canadian Cardiovascular Society functional classification. ${ }^{13}$ Some 116 patients $(71 \%)$ had multivessel disease, $44(27 \%)$ underwent multivessel, and $62(38 \%)$ underwent multilesion coronary angioplasty during the same procedure. A mean of 1.3 vessels and 1.4 stenoses per patient were dilated. A history of hypertension was present in 29 patients $(18 \%)$, diabetes mellitus in $12(7 \%)$, and hypercholesterolaemia in $75(46 \%)$. Seventy five patients $(46 \%)$ were current smokers.

\section{ANGIOPLASTY PROCEDURE}

Coronary angioplasty was performed according to a previously described protocol. ${ }^{14}$ The femoral approach was used in all cases. All patients received oral aspirin and most patients were sedated with intravenous diazepam. Intra-arterial heparin (10 000 units) was administered at the start of the procedure. Additional boluses were given to maintain an activated clotting time of $>300 \mathrm{~s}$. Adaptations were made throughout the study period to accommodate technical advances such as the development of low profile, steerable balloon catheters. Balloon size was selected to approximate the diameter of the adjacent normal segment of the coronary artery. The femoral sheath was left in place

Table 1 Patient characteristics

\begin{tabular}{ll}
\hline & $N o$ \\
\hline Patients & $163(100)$ \\
Male gender & $102(63)$ \\
Mean (SD) (range) age (years) & $73(3)(70-83)$ \\
Previous MI & $74(45)$ \\
Angina grade & $12(7)$ \\
O/I & $34(21)$ \\
II & $49(30)$ \\
III & $68(42)$ \\
IV & $27(17)$ \\
Unstable angina & $66(40)$ \\
Abnormal LV (EF < 45\%) & $47(29)$ \\
No of diseased vessels & $58(36)$ \\
1 & $58(36)$ \\
2 & $28(17)$ \\
3 & $119(73)$ \\
Previous CABG & $44(27)$ \\
Single vessel PTCA & $62(38)$ \\
Multivessel PTCA & $29(18)$ \\
Multilesion PTCA & $12(7)$ \\
Risk factors & $75(46)$ \\
Hypertension & $75(46)$ \\
Diabetes mellitus & \\
Current smoking & \\
Hypercholesterolaemia & \\
\hline
\end{tabular}

Values in parentheses are percentages.

CABG, coronary artery bypass surgery; EF, ejection fraction LV, left ventricular function; MI, myocardial infarction PTCA, percutaneous transluminal coronary angioplasty. for $4 \mathrm{~h}$ after angioplasty, and intravenous infusions of heparin and nitrate were continued for $24 \mathrm{~h}$.

Coronary angioplasty was attempted in 213 vessels including two $(1 \%)$ protected left main stem, $102(48 \%)$ left anterior descending artery and its diagonal branches, eight (4\%) intermediate artery, $41(19 \%)$ circumflex artery and its obtuse marginal branches, 53 $(25 \%)$ right coronary artery, and seven $(3 \%)$ saphenous vein grafts. Twenty two procedures were undertaken for totally occluded vessels. A total of 275 lesions were attempted.

\section{STUDY METHODS}

The baseline characteristics, procedural, and angiographic data on all 163 patients were assessed. Hand held callipers were used for measuring diameters from the projected angiographic film using the image of the guiding catheter for magnification scaling. Complete follow up data were available on all patients, obtained at routine clinic visits, from the referring physicians, and by telephone interview with the patients. Information on vital status, current angina status, and the occurrence of new cardiac events (defined as death, myocardial infarction, coronary artery bypass grafting, or repeat coronary angioplasty) was obtained up to July 1993. The cause of any death was fully established and classified as cardiac or non-cardiac. The indication for follow up coronary angiography was strictly clinical: recurrence of angina pectoris or a positive symptom limited treadmill exercise test performed routinely during outpatient visits.

\section{DEFINITIONS}

Angiographic success was defined as $\leqslant 50 \%$ residual diameter stenosis at the dilated sites. Procedural success occurred when a patient had angiographic success in at least one vessel without a major complication, defined as death, myocardial infarction, or emergency coronary artery bypass grafting, at any time during hospitalisation. Unstable angina pectoris was defined as angina occurring at rest requiring intravenous medical treatment and included patients with post-infarction angina pectoris. Complete revascularisation was defined as successful dilatation of all lesions $>50 \%$ luminal diameter stenosis.

\section{STATISTICAL METHODS}

Continuous variables are expressed as mean (SD). Categorical variables were compared using the $\chi^{2}$ test for trend or Fisher's exact test (two sided) and continuous variables using the unpaired $t$ test. A p value of $<0.05$ was considered significant. Life table analyses were performed using the Kaplan-Meier method, computed from the time of coronary angioplasty. The log rank test and proportional hazards regression analysis were used to identify which prognostic factors independently influenced long-term survival and the time to a cardiac event during follow up; prognostic factors were selected using the backwards stepwise procedure. 
Table 2 Primary angiographic success for all 275 lesions

\begin{tabular}{lcc}
\hline & $\begin{array}{c}\text { No of } \\
\text { lesions }\end{array}$ & $\begin{array}{l}\text { Angiographic } \\
\text { success }\end{array}$ \\
\hline LMS & 2 & $2(100)$ \\
LAD & 128 & $112(88)$ \\
RCA & 75 & $66(88)$ \\
CX & 53 & $48(91)$ \\
INT & 9 & $9(100)$ \\
TVG & 8 & $6(75)$ \\
Totally occluded lesions & 29 & $17(59)$ \\
Non-occluded lesions & 246 & $226(92)$ \\
Total & 275 & $243(88)$ \\
\hline
\end{tabular}

Values in parentheses are percentages.

$\mathrm{CX}$, circumflex artery; INT, intermediate artery; $\mathrm{LAD}$, lef anterior descending artery; LMS, left main stem; RCA, right coronary artery; SVG, saphenous vein graft.

\section{Results}

ACUTE RESULTS

Angiographic success was achieved in 183 vessels $(86 \%)$ and 243 lesions $(88 \%)$. The angiographic success rate was $92 \%$ for nonoccluded lesions and $59 \%$ for totally occluded lesions. Table 2 gives the distribution of the lesions and the success rate per lesion. An abrupt closure occurred in 13 lesions. Nineteen lesions could not be crossed of which 12 were chronic total occlusions. Revascularisation was complete in only 70 patients (43\%) and incomplete in 93 patients (57\%). Complete revascularisation was lowest in patients with triple vessel disease $(14 \%)$, intermediate $(36 \%)$ in those with double vessel disease, and highest $(87 \%)$ in patients with single vessel disease $(P<0.001)$.

Procedural success was achieved in 134 patients $(82 \%)$. The procedural success rate was $85 \%$ for those patients who were aged 70-74 years, $73 \%$ for those aged $75-79$ years, and $50 \%$ for those aged $>80$ years.

Table 3 Variables associated with acute angioplasty and complications

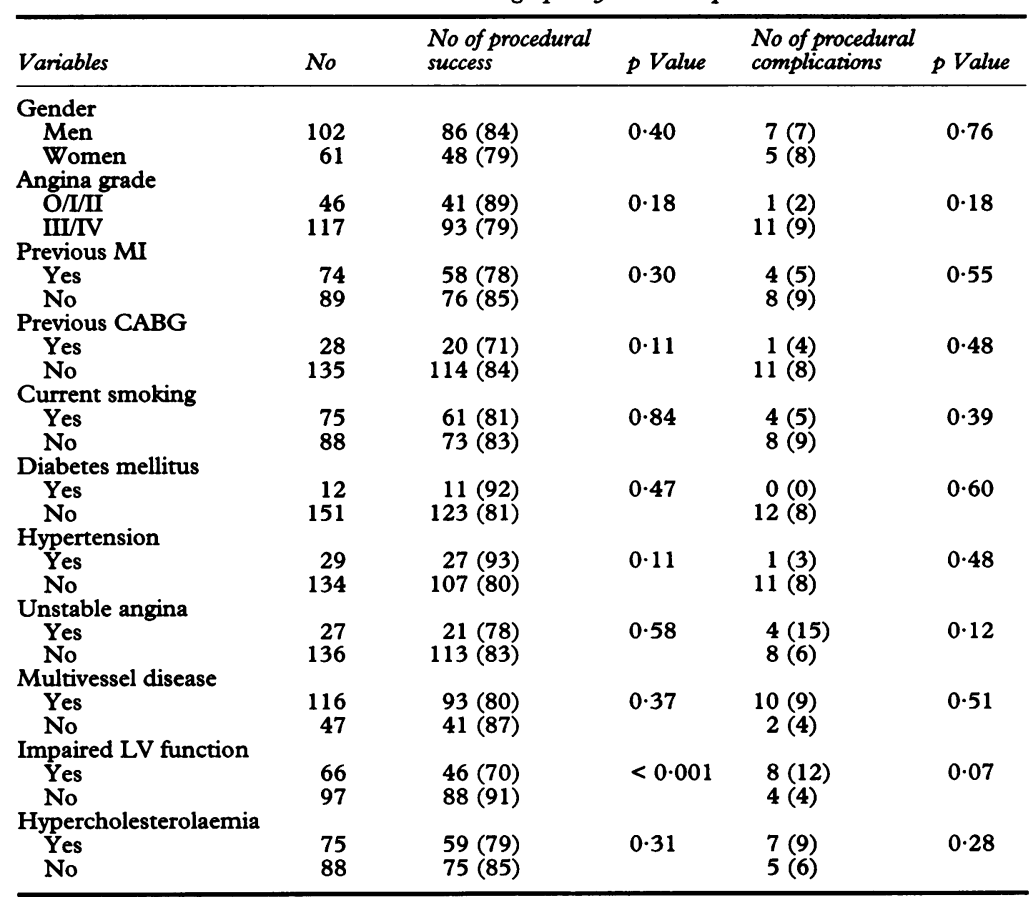

Values in parentheses are percentages.

Abbreviations as in table 1 .
A significant complication occurred in 12 patients (7\%), which was invariably the result of an abrupt occlusion of the vessel being dilated. Four patients $(2 \%)$ died, three $(2 \%)$ suffered a non-fatal $Q$ wave myocardial infarction, and five (3\%) underwent emergency coronary artery bypass grafting. The four patients who died had greatly impaired left ventricular function; three of them had triple vessel disease. They were not considered candidates for bypass grafting because of a high surgical risk. Seventeen patients $(10 \%)$ had an unsuccessful but uncomplicated angioplasty. None of the patients suffered an irreversible cerebrovascular accident.

DETERMINANTS OF PROCEDURAL OUTCOME

Table 3 gives the 11 variables that were analysed to assess their association with procedural outcome. Patients with impaired left ventricular function had a significantly lower procedural success rate $(70 \% v 91 \%, \mathrm{P}<$ $0.001)$ and a suggestion of a higher complication rate $(12 \% v 4 \%, \mathrm{P}=0.07)$ than those with well preserved left ventricular function. None of the other variables analysed were significantly associated with procedural outcome.

\section{LONG-TERM RESULTS}

Complete follow up data were available for all 163 patients on or after the census date. The median (range) duration of follow up was 35 (2-146) months. During the follow up period, 16 patients (10\%) died, two (1\%) suffered non-fatal myocardial infarction, and $12(7 \%)$ underwent elective coronary artery bypass grafting. A second coronary angioplasty procedure was performed in 24 patients $(15 \%)$ with procedural success in 22 . In total, a second revascularisation procedure was necessary in 36 patients $(22 \%)$. The 16 late deaths included four non-cardiac deaths (bronchopneumonia, carcinoma of the colon, acute leukaemia, and cerebrovascular accident) and eight cardiac deaths (two sudden deaths and six fatal myocardial infarctions). Four patients died as a result of additional revascularisation procedures.

The cumulative probability of survival for 163 patients was $90.7 \%$ (SE $2.4 \%$ ) and $83.4 \%$ (SE $3.7 \%$ ) at 1 and 5 years, respectively (table 4). Patients with initially successful angioplasty procedures had cumulative 1 and 5 year survival rates of $93.9 \%$ (SE $2.3 \%$ ) and $85 \cdot 7 \%$ (SE $4 \cdot 1 \%$ ), respectively. The 1 and 5 year cumulative event free survival rates are shown in table 4 for all patients and patients with initially successful angioplasty procedures (fig 1).

At census, of the 143 survivors, 75 (52\%) were asymptomatic, $58(41 \%)$ had mild angina, and only $10(7 \%)$ complained of grade III or IV angina (fig 2). Some 112 patients $(78 \%)$ improved by at least two angina grades.

DETERMINANTS OF LONG-TERM SURVIVAL

Variables examined to determine predictors for overall and event free survival (freedom 
Table 4 Total and event free survival rates at 1 and 5 years after percutaneous transluminal coronary angioplasty for all patients and those with initially successful angioplasty procedures.

\begin{tabular}{|c|c|c|c|c|}
\hline & \multicolumn{2}{|l|}{ One year } & \multicolumn{2}{|l|}{ Five years } \\
\hline & All patients & $\begin{array}{l}\text { Procedural } \\
\text { success }\end{array}$ & All patients & $\begin{array}{l}\text { Procedural } \\
\text { success }\end{array}$ \\
\hline $\begin{array}{l}\text { Survival (\%) } \\
\text { Freedom from death/MI (\%) } \\
\text { Freedom from death/MU/CABG (\%) } \\
\text { Freedom from death/MU/CABG/PTCA (\%) } \\
\text { Freedom from CABG }(\%) \\
\text { Freedom from repeat PTCA (\%) } \\
\text { Freedom from CABG/repeat PTCA (\%) }\end{array}$ & $\begin{array}{l}90 \cdot 7(85 \cdot 9-95 \cdot 5) \\
88 \cdot 3(83 \cdot 1-93 \cdot 5) \\
80 \cdot 6(74 \cdot 2-87 \cdot 0) \\
68 \cdot 2(60 \cdot 7-75 \cdot 7) \\
89 \cdot 9(85 \cdot 0-94 \cdot 7) \\
86 \cdot 8(81 \cdot 4-92 \cdot 2) \\
76 \cdot 0(69 \cdot 1-83 \cdot 0)\end{array}$ & $\begin{array}{l}93 \cdot 9(89 \cdot 4-98 \cdot 4) \\
94 \cdot 0(89 \cdot 6-98 \cdot 4) \\
91 \cdot 6(86 \cdot 5-96 \cdot 7) \\
77 \cdot 1(69 \cdot 6-84 \cdot 6) \\
96 \cdot 7(93 \cdot 4-100) \\
85 \cdot 5(79 \cdot 3-91 \cdot 7) \\
82 \cdot 1(75 \cdot 3-88 \cdot 9)\end{array}$ & $\begin{array}{l}83 \cdot 4(76 \cdot 1-90 \cdot 7) \\
79 \cdot 3(71 \cdot 2-87 \cdot 4) \\
70 \cdot 5(61 \cdot 3-79 \cdot 7) \\
56 \cdot 0(46 \cdot 3-65 \cdot 7) \\
87 \cdot 2(81 \cdot 3-93 \cdot 2) \\
83 \cdot 8(77 \cdot 6-90 \cdot 0) \\
70 \cdot 5(62 \cdot 1-78 \cdot 9)\end{array}$ & $\begin{array}{l}85 \cdot 7(77 \cdot 5-93 \cdot 9) \\
83 \cdot 8(74 \cdot 9-92 \cdot 7) \\
79 \cdot 2(69 \cdot 3-89 \cdot 1) \\
62 \cdot 3(51 \cdot 3-73 \cdot 3) \\
93 \cdot 4(87 \cdot 8-99 \cdot 0) \\
83 \cdot 0(76 \cdot 0-90 \cdot 0) \\
75 \cdot 3(66 \cdot 2-84 \cdot 4)\end{array}$ \\
\hline
\end{tabular}

Values in parentheses are $95 \%$ confidence intervals.

Abbreviations as in table 1 .

Figure 1 Cumulative total and event free survival rates for 163 patients who underwent percutaneous transluminal coronary balloon angioplasty. Dth, freedom from death; Dth/MI, freedom from death and myocardial infarction; Dth/MI/CABG freedom from death, myocardial infarction, and bypass grafting: freedom from death myocardial infarction, bypass grafting, and repeat coronary angioplasty Dth/MI/CABG/PTCA,

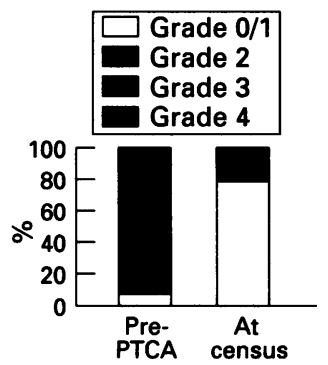

Figure 2 Angina grade before coronary angioplasty (pre-PTCA) and at census $(P<0.001)$ in 143 survivors

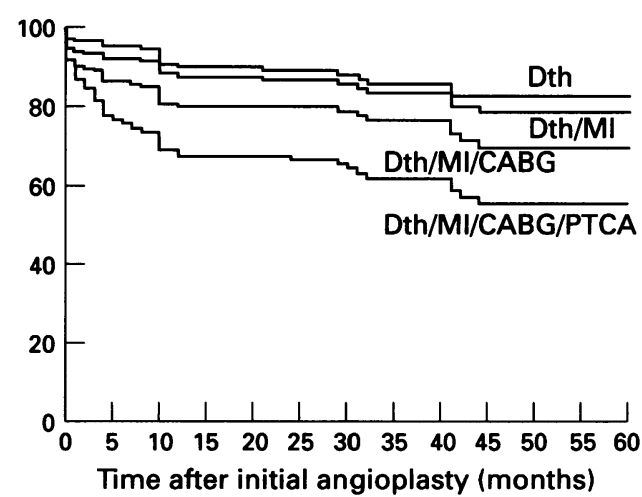

from death, myocardial infarction, bypass surgery, and repeat angioplasty) were: age; impaired left ventricular function (ejection fraction $<45 \%$ ); extent of native vessel disease (single $v$ multivessel disease); prior coronary artery bypass surgery; stable versus unstable angina pectoris; presence of diabetes mellitus; and completeness of revascularisation.

Individual survival analyses showed that incomplete revascularisation $(P=0.014)$, impaired left ventricular function $(P=0.01)$, multivessel vessel disease $(P<0.001)$, and prior coronary artery bypass grafting $(\mathbf{P}=$ 0.01 ) were negative correlates for overall survival. Incomplete revascularisation $(\mathrm{P}<$ $0.001)$ and impaired left ventricular function $(P=0.01)$ were also shown to be negative correlates for event free survival.

Proportional hazards regression analyses identified incomplete revascularisation as the only independent predictor of poorer overall survival $(P=0.04)$ and event free survival

Figure 3 Cumulative survival according to the completeness of revascularisation $(P=0.014)$. Revasc, revascularisation

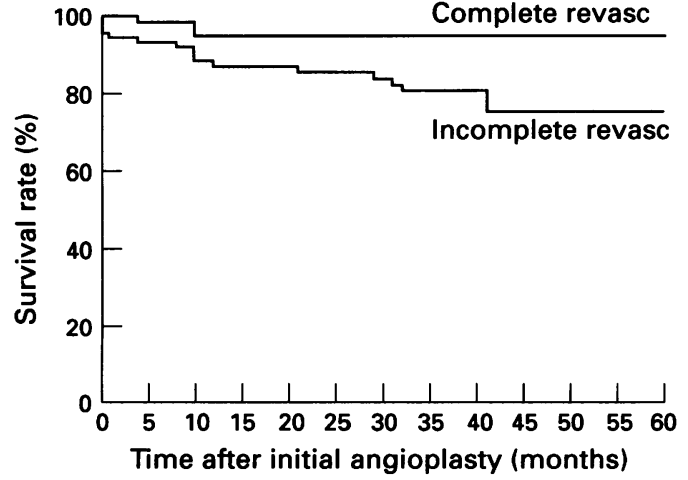

$(P<0.001)$ (figs 3 and 4 ). The incidence of late cardiac events (death, myocardial infarction, coronary artery bypass surgery, or repeat angioplasty) was $21 \%$ in patients with complete revascularisation and $47 \%$ in those with incomplete revascularisation.

\section{Discussion}

The proportion of elderly patients with symptomatic coronary artery disease continues to expand with an increasing average life expectancy. As a result, more and more are subjected to invasive diagnostic and therapeutic interventions. One third of cardiac catheterisations and bypass operations in the United States are performed on elderly patients. ${ }^{1516}$ The need for myocardial revascularisation in symptomatic elderly patients is not in dispute, but the safety and efficacy of the various therapeutic modalities need to be evaluated in these seemingly fragile patients. Although surgical studies have reported improved symptoms and survival in this subset of patients, ${ }^{21718}$ the operative mortality and morbidity are high. ${ }^{219} 20$ Percutaneous transluminal coronary angioplasty has proved a safe and effective method of myocardial revascularisation. Despite being extended to more complex cases the continued refinement in balloon angioplasty technique, greater operator experience, and equipment evolution have led to improved angioplasty outcome. As a result, patients at high risk for cardiac surgery, including the elderly, have been increasingly treated with coronary angioplasty in recent years.

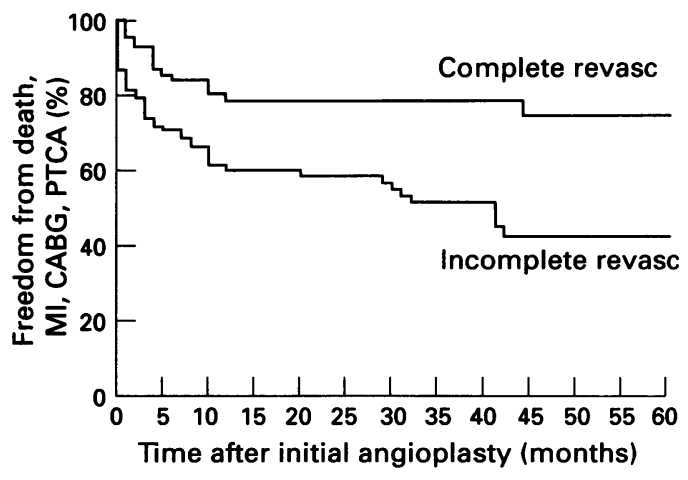

Figure 4 Patients free from death, myocardial infarction (MI), bypass surgery (CABG), and repeat angioplasty. (PTCA) according to the completeness of revascularisation $(P<0.001)$. Revasc, revascularisation 
Table 5 Other published results

\begin{tabular}{|c|c|c|c|c|c|c|c|c|}
\hline $\begin{array}{l}\text { Reference } \\
\text { (year) }\end{array}$ & Year & $\begin{array}{l}\text { Age } \\
\text { (years) }\end{array}$ & No of patients & $\begin{array}{l}\text { Angiographic } \\
\text { success (\%) }\end{array}$ & $\begin{array}{l}\text { Procedural } \\
\text { success (\%) }\end{array}$ & Death (\%) & $A M I(\%)$ & $C A B G(\%)$ \\
\hline $\begin{array}{l}\text { Mock, et al }{ }^{10} \\
\text { Jones, et } a l^{21} \\
\text { Raizner, et } a l^{22} \\
\text { Urban, et } a l^{23} \\
\text { Bedotto, et } a l^{24} \\
\text { Thompson, et } a l^{25}\end{array}$ & $\begin{array}{l}1984 \\
1986 \\
1986 \\
1987 \\
1991 \\
1991\end{array}$ & $\begin{array}{l}\geqslant 65 \\
\geqslant 65 \\
\geqslant 65 \\
\geqslant 65 \\
\geqslant 65 \\
\geqslant 65\end{array}$ & $\begin{array}{r}370 \\
159 \\
119 \\
51 \\
1373 \\
752\end{array}$ & $\begin{array}{l}\overline{84} \\
\overline{81} \\
\overline{96} \\
-\end{array}$ & $\begin{array}{l}53 \\
81 \\
\overline{71} \\
\frac{85}{85}\end{array}$ & $\begin{array}{l}2 \cdot 2 \\
0 \cdot 0 \\
0 \cdot 8 \\
4 \cdot 6 \\
1 \cdot 6 \\
2 \cdot 8\end{array}$ & $\begin{array}{l}5 \cdot 6 \\
3 \cdot 1 \\
2 \cdot 5 \\
4 \cdot 6 \\
1 \cdot 4 \\
4 \cdot 3\end{array}$ & $\begin{array}{l}6 \cdot 8 \\
5 \cdot 7 \\
4 \cdot 1 \\
4 \cdot 6 \\
0 \cdot 8 \\
8 \cdot 2\end{array}$ \\
\hline $\begin{array}{l}\text { Dorros and Janke } \\
\text { Hartzler, } \text { et } \mathrm{l}^{7} \\
\text { Holt, et al } \\
\text { Simpfendorfer, et } a l^{11} \\
\text { Dorros, } \text { et }^{26} l^{27} \\
\text { de Jaegere, } \text { et }^{28} l^{28} \\
\text { Maiello, et al }{ }^{29} \\
\text { Present study }\end{array}$ & $\begin{array}{l}1986 \\
1988 \\
1988 \\
1988 \\
\\
1989 \\
1992 \\
1992\end{array}$ & $\begin{array}{l}\geqslant 70 \\
\geqslant 70 \\
\geqslant 70 \\
\geqslant 70 \\
\geqslant 70 \\
\geqslant 70 \\
\geqslant 70 \\
\geqslant 70 \\
\geqslant 70\end{array}$ & $\begin{array}{c}109 \\
1038 \\
54^{\star} \\
124 \dagger \\
212^{\star} \\
242 \\
166 \\
92 \\
163\end{array}$ & $\begin{array}{l}89 \\
94 \\
- \\
- \\
\overline{-} \\
91 \\
85 \\
92 \\
86\end{array}$ & $\begin{array}{l}83 \\
80 \\
90 \\
93 \\
86 \\
86 \\
83 \\
82\end{array}$ & $\begin{array}{l}1 \cdot 8 \\
1 \cdot 4 \\
0 \cdot 0 \\
0 \cdot 0 \\
0 \cdot 9 \\
3 \cdot 3 \\
2 \cdot 4 \\
5 \cdot 4 \\
2 \cdot 4\end{array}$ & $\begin{array}{l}2 \cdot 8 \\
0 \cdot 8 \\
4 \cdot 0 \\
0 \cdot 8 \\
0 \cdot 9 \\
2 \cdot 1 \\
3 \cdot 0 \\
1 \cdot 1 \\
1 \cdot 8\end{array}$ & $\begin{array}{l}0 \cdot 9 \\
1 \cdot 3 \\
6 \cdot 0 \\
4 \cdot 0 \\
2 \cdot 8 \\
1 \cdot 2 \\
3 \cdot 6 \\
3 \cdot 2 \\
3 \cdot 1\end{array}$ \\
\hline Imburgia, et al ${ }^{12}$ & 1989 & $\geqslant 75$ & 43 & 68 & 57 & $6 \cdot 0$ & $2 \cdot 0$ & $8 \cdot 0$ \\
\hline $\begin{array}{l}\text { Kern, et } a l^{30} \\
\text { Rich, et al } \\
\text { Rizo-Patron, et } a l^{32} \\
\text { Jeroudi, et al } \\
\text { Santana, et } a l^{34}\end{array}$ & $\begin{array}{l}1988 \\
1990 \\
1990 \\
1990 \\
1992\end{array}$ & $\begin{array}{l}\geqslant 80 \\
\geqslant 80 \\
\geqslant 80 \\
\geqslant 80 \\
\geqslant 80\end{array}$ & $\begin{array}{l}21 \\
22 \\
53^{\star} \\
54 \\
53^{\star}\end{array}$ & $\begin{array}{l}78 \\
89 \\
93 \\
83\end{array}$ & $\begin{array}{l}\frac{67}{83} \\
91 \\
-\end{array}$ & $\begin{array}{r}19 \\
0 \cdot 0 \\
1 \cdot 8 \\
4 \cdot 0 \\
15 \cdot 1\end{array}$ & $\begin{array}{r}\overline{14 \cdot 0} \\
5 \cdot 5 \\
4 \cdot 0 \\
3 \cdot 8\end{array}$ & $\begin{array}{c}14 \\
0.0 \\
7.5 \\
0.0 \\
-\end{array}$ \\
\hline
\end{tabular}

* Patients with unstable angina; tpatients with stable angina

AMI, acute myocardial infarction; CABG, emergency coronary artery bypass surgery.

ACUTE RESULTS

The acute success and complication rates achieved in this study are comparable with those of other centres (table 5). Previous studies of coronary angioplasty in elderly patients have reported angiographic success rates ranging from $68 \%$ to $96 \%$, procedural success rates from $53 \%$ to $93 \%$, mortalities from $0 \%$ to $15 \cdot 1 \%$, myocardial infarction rates from $0 \cdot 8 \%$ to $14 \%$, and emergency bypass surgery rates from $0 \%$ to $8 \cdot 2 \% .^{15-33}$ The low procedural success rate of $53 \%$ and the high complication rate reported by Mock et $a l^{10}$ on behalf of the National Heart, Lung, and Blood Institute Percutaneous Transluminal Coronary Angioplasty Registry represent an early multicentre experience circa 1977-1981. Considerable advances in angioplasty technology and operator experience have occurred since that period. More recently, Simpfendorfer et $a l^{11}$ reported a high procedural success rate of $93 \%$ with the lowest rate of major cardiac complications among previously reported studies. However, only $23 \%$ of their patients had multivessel disease as opposed to $71 \%$ in the present study, which might explain their more favourable results.

Although the overall angiographic success rate achieved in the present study was only $88 \%$, most failures occurred in occluded lesions. Angioplasty was technically successful in $92 \%$ of non-occluded lesions, suggesting that the procedure is technically feasible in elderly patients despite the higher incidence of clinical and lesion measurements which are considered as less than ideal for angioplasty. Earlier studies have suggested that coronary balloon angioplasty in elderly patients is associated with lower success and higher complication rates compared with those achieved in younger patients. ${ }^{10}$ The initial report from the National Heart, Lung, and Blood Institute Percutaneous Transluminal Coronary Angioplasty Registry reported procedural success rates of $53 \%$ and $62 \%$, and mortality rates of $2 \cdot 2 \%$ and $0 \cdot 7 \%$, in patients aged $\geqslant 65$ years and $<65$ years, respectively. ${ }^{10}$ Such differences, however, have not been confirmed in recent studies, which have reported high technical success rates in elderly patients. ${ }^{2122}$ This may be explained by the differences in baseline characteristics of the study population due to selection bias, improvement in patient selection, or advances in angioplasty technology and operator experience resulting in the improved primary success rates.

Despite the presence of multivessel disease in $71 \%$ of the patients only $27 \%$ underwent multivessel coronary angioplasty in the present study. Complete revascularisation was achieved in only $43 \%$ of the patients, and was lowest in patients who had three vessel disease. These findings are similar to those of earlier studies. ${ }^{35}{ }^{36}$ Coronary angioplasty was frequently chosen as an alternative mode of revascularisation when surgery was considered too risky because of haemodynamic instability or other concurrent medical problems commonly found in elderly patients. In such high risk patients, coronary angioplasty was frequently performed on the "culprit" lesion (usually, but not always, the most critical lesion) to achieve symptomatic improvement, without attempting to accomplish complete revascularisation. This approach towards coronary angioplasty in the elderly reduces the length of procedure and the amount of contrast utilised, hence minimising the risk of complication.

DETERMINANTS OF PROCEDURAL OUTCOME The presence of impaired left ventricular function was significantly associated with a lower procedural success and a trend towards a higher complication rate. Similar results have been shown by other investigators. ${ }^{7738}$ Coronary angioplasty in patients with left ventricular dysfunction is associated with multiple technical difficulties, resulting from poor tolerance of any reduction in coronary flow, either transiently during balloon inflation or more prolonged in the event of an abrupt 
closure. The recent introduction of new angioplasty technology, such as autoperfusion balloon catheters (which allow prolonged inflations without interruption of anterograde flow), intravascular stents, and directional atherectomy (both of which enable re-establishment of anterograde flow in the event of dissection leading to abrupt closure), has improved procedural outcome. ${ }^{39-41}$ Furthermore, the use of supported angioplasty with intra-aortic balloon pump or partial cardiopulmonary bypass has further enhanced the procedural safety of coronary angioplasty in these patients. ${ }^{42} 43$

In the absence of randomised studies, direct comparison of these results with those achieved with coronary bypass surgery may be misleading because of the possibility of selection bias resulting from differences in baseline and procedural variations. However, a higher risk of surgical mortality (ranging from $2 \cdot 3 \%$ to $12 \%)^{2320}$ and perioperative morbidity (ranging from 14 to $65 \%$ ) in the elderly has been confirmed, although more recent surgical studies have shown an improved survival rate compared with that of earlier reports. ${ }^{44} 45$ Angioplasty, when successful, is associated with less morbidity than bypass surgery, and is therefore potentially more attractive. Of particular note is that none of the patients in the present series and in those described previously ${ }^{11}$ suffered an irreversible cerebrovascular accident as opposed to the $2 \cdot 7-7 \cdot 5 \%$ reported in surgical studies. ${ }^{417}$

\section{LONG-TERM FOLLOW UP}

Although angioplasty in the elderly is technically feasible, the procedure must be associated with short- and long-term symptomatic improvement before being judged clinically successful. This study has shown that the long-term survival of patients who undergo coronary angioplasty is influenced by the completeness of revascularisation. Survival may also be influenced by the risk of restenosis, which might be increased in the elderly. Information on the restenosis rate, however, was not available in this study due to the low incidence of follow up angiography; angiography being repeated only when it was clinically indicated. Despite the presence of multivessel disease and incomplete revascularisation in the majority of patients the overall rate of survival at one and five years was encouraging, and rivalled those reported for elderly patients undergoing coronary bypass surgery. ${ }^{217}$ This favourable long-term survival has also been substantiated by previous coronary angioplasty studies, which have shown a remarkable similarity in the overall and event free survival rates. ${ }^{11} 2627$ de Jaegere et al ${ }^{28}$ reported overall survival of $89 \%$ and event free survival (freedom from death, myocardial infarction, bypass surgery, and repeat angioplasty) of $61 \%$ at 4 years after the primary procedure in 166 patients aged 70 and over. Bedotto et al ${ }^{24}$ showed actuarial survival rates of $92 \%$ and $78 \%$ at one and five years respectively in 1373 patients aged 65 years and older. Freedom from death, myocardial infarction, and coro- nary bypass surgery was $81 \%$ at one year and $56 \%$ at five years. Dorros et $a l^{27}$ reported a six year overall survival rate of $92 \%$ and freedom from death, myocardial infarction, or bypass surgery was $73 \%$ in 242 patients over the age of 70 . The present study has shown an overall survival of $91 \%$ at one year and $83 \%$ at five years. The one and five year rates for freedom from death, myocardial infarction, and coronary bypass surgery were $81 \%$ and $71 \%$, respectively. The rates for freedom from death, myocardial infarction, coronary bypass surgery, and repeat angioplasty was $68 \%$ at one year and $56 \%$ at five years.

DETERMINANTS OF LONG-TERM SURVIVAL

Although complete revascularisation was achieved in less than half of the patients, the patients' quality of remaining life appeared good with marked improvement in angina status: prior to angioplasty $72 \%$ of patients had severe angina, but at census $52 \%$ were asymptomatic and $78 \%$ were improved by at least two angina grades.

However, the incidence of late cardiac events was also significantly higher in patients who had incomplete revascularisation compared with those with complete revascularisation. It appeared that dilatation of only the culprit lesion provided adequate relief of ischaemia and led to sufficient and often dramatic clinical improvement, but often at the expense of a higher incidence of late cardiac events and less favourable long-term survival. Although a subsequent revascularisation procedure was necessary in $22 \%$ of patients, only $7 \%$ needed elective coronary artery bypass surgery. Hence, achieving complete revascularisation in the elderly population may not be necessary if the primary therapeutic goal is to provide symptomatic relief and improvement in the quality of life.

The findings in this study are consistent with previous surgical ${ }^{46-48}$ and angioplasty ${ }^{63649}$ studies, which have shown that patients with multivessel disease, in whom revascularisation was incomplete, have generally poor symptomatic relief and survival. However, the clinical importance of the completeness of revascularisation in the elderly population on long-term outcome remains controversial. Bedotto et $a l^{24}$ have shown that long-term survival after coronary angioplasty in elderly patients was significantly influenced by the degree of revascularisation. Maiello et $a l^{29}$ reported a higher trend towards increased cardiac events in patients with partial revascularisation. On the other hand, de Jaegere et $a l^{28}$ showed that the degree of revascularisation did not influence event free survival. These discrepancies may be explained by variation in the baseline patient characteristics, or by differences in the functional significance of the remaining stenoses in patients with incomplete revascularisation. ${ }^{50}$

\section{STUDY LIMITATIONS}

This study is a retrospective analysis of data which were collected prospectively and is subject to all the limitations inherent in such a 
study. As it was not a randomised study, no attempt was made to compare the results with those achieved with coronary artery bypass grafting, as selection criteria may not have been identical.

\section{Conclusions}

Medical treatment is often poorly tolerated by the elderly and side effects from drugs are common. The enthusiasm for surgical revascularisation, although effective in relieving symptoms and improving prognosis, has been tempered by the higher mortality and morbidity in this population. Our data have shown that coronary angioplasty can be performed safely and effectively in selected elderly patients, and provides good symptomatic relief and favourable long-term outcome. This procedure, when feasible, provides an attractive alternative to coronary bypass surgery in this group of patients. Until results of randomised trials are available, this study provides useful information in helping clinicians decide on the optimal method of revascularisation in elderly patients.

We thank Lisa Goodall for her technical assistance and data collection, and all the consultants working at Guy's Hospital for allowing us to study their patients.

1 Moritz DJ, Ostfeld AM. The epidemiology and demography of aging. In: Hazzard WR, Andres $R$, Bierman EL, Blass JP, eds. Principles of geriatric medicine and geronEL, Blass JP, eds. Principles of geriatric medicine

2 Gersh RJ, Kronmal RA, Schaff HV, et al and the participants in the coronary artery surgery study. Comparison of coronary artery bypass surgery and medical therapy in patients 65 years of age or older: a nonrandomized study from the Coronary Artery Surgery Study (CASS) Registry. $N$ Engl f Med 1985;313:217-24.

3 Loop FD, Lytle BW, Cosgrove DM, et al. Coronary artery bypass graft surgery in the elderly. Cleve Clin $\mathcal{f} \mathrm{Med}$ 1988;55:23-4.

4 Grondin CM, Thornton JC, Engle JC, Schreiber H, Cross FS. Cardiac surgery in septuagenarians: is there a difference in mortality and

5 Nolan L, O'Malley K. Prescribing for the elderly. Part 1 Sensitivity of the elderly to adverse drug reactions. $\mathcal{f} \mathrm{Am}$ Geriatr Soc 1988;36:142-9.

6 O'Keefe JH, Rutherford BD, McConahay DR, et al. Multivessel coronary angioplasty from 1980 to 1989 : procedural results and long-term outcome. $f \mathrm{Am} \mathrm{Coll}$ procedural results and 100 1990;16:1097-102.

7 Hartzler GO, Rutherford BD, McConahay DR, Johnson WL, Giorgi LV. "High risk" percutaneous transluminal WL, Giorgi LV. "High risk" percutaneous translum

8 Kelly ME, Taylor GJ, Moses HW, et al. Comparative cost of myocardial revascularization: percutaneous transluminal angioplasty and coronary artery bypass surgery. $\mathcal{f ~} \mathrm{Am}$ Coll Cardiol 1985;5:16-20.

9 Dorros G, Janke L. Percutaneous transluminal coronary angioplasty in patients over the age of 70 years. Cathet Cardiovasc Diagn 1986;12:223-9.

10 Mock MB, Holmes DR Jr, Vlietstra RE, et al. Percutaneous transluminal coronary angioplasty (PTCA) in the elderly patients: experience in the Registry. Am $\mathcal{F}$ Cardiol 1984;53:89-91C

11 Simpfendorfer C, Raymond R, Schraider J, et al. Early and long-term results of percutaneous transluminal coronary angioplasty in patients 70 years of age and older with angina pectoris. Am $\mathcal{f}$ Cardiol 1988;62:959-61.

12 Imburgia M, King TR, Soffer AD, Rich MW, Krone RJ, Salimi A. Early results and long-term outcome of percutaneous transluminal coronary angioplasty in patients age 70 years or older. Am $₹$ Cardiol 1989;63:1127-9.

13 Campeau L. Grading of angina pectoris. Circulation 1976; 54:522-3.

14 Sowton E, Timmis AD, Crick JCP, Griffin B, Yates AK Deverall $P$. Early results after percutaneous transluminal Deverall $P$. Early results after percutaneous transluminal 56:115-20.
15 Kashyap M. Cardiovascular disease in the elderly: current considerations. Am ₹ Cardiol 1989;63:3-4H.

16 Stason WB, Sanders CA, Smith HC. Cardiovascular care of the elderly: economic considerations. $\mathcal{f} \mathrm{Am}$ Coll Cardiol 1987;10:18-21A.

17 Horneffer PJ, Gardner TJ, Manolio TA, et al. The effects of age on outcome after coronary bypass surgery. Circulation 1987;76(suppl V):V6-12.

18 Elayda MS, Hall RJ, Gray AG, Mathur VS, Cooley DA. Coronary revascularization in the elderly patients. $\mathcal{F} \mathrm{Am}$ Coll Cardiol 1984;3:1398-402.

19 Kennedy JW, Kaider GC, Fisher LD, et al. Clinical and angiographic predictors of operative mortality from the collaborative study in coronary artery surgery. Circulation 1981;63:793-802.

20 Hochberg MS, Levine FH, Daggett WM, Akins CW, Austen WG, Buckley MJ. Isolated coronary artery bypass grafting in patients seventy years of age and older: early and late results. $\mathcal{F}$ Thorac Cardiovasc Surg 1982;84: 219-23.

21 Jones EL, Abi-Mansour P, Gruentzig AR. Coronary artery bypass surgery and percutaneous transluminal coronary angioplasty in the elderly patient. Cardiology 1986;73: 223-34.

22 Raizner AE, Hust RG, Lewis JM, Winters WL Jr, Batty JW, Roberts R. Transluminal coronary angioplasty in the elderly. Am f Cardiol 1986;57:29-32.

23 Urban P, Fox K, Crean P, Shapiro L, Rickards A. Coronary balloon angioplasty for elderly patients with severe angina. Br Heart f 1987;58:465-8.

24 Bedotto JB, Rutherford BD, McConahay DR, et al. Results of multivessel percutaneous transluminal coronary angioplasty in persons aged 65 years and older. $\mathrm{Am}$ f Cardiol 1991;67:1051-5.

25 Thompson RC, Holmes DR Jr, Gersh BJ, Mock MB, Bailey KR. Percutaneous transluminal coronary angioplasty in the elderly: early and long-term results. $\mathcal{f} \mathrm{Am}$ poll Cardiol 1991;17:1245-50.

26 Holt GW, Sugrue DD, Bresnahan JF, et al. Results of percutaneous transluminal coronary angioplasty for unstable angina pectoris in patients 70 years of age and older. Am f Cardiol 1988;61:994-7.

27 Dorros G, Lewin RF, Mathiak LM. Percutaneous transluminal coronary angioplasty in patients over the age of 70 years. Cardiol Clin 1989;4:805-12.

28 de Jaegere $P$, de Feyter $P$, van Domburg R, Suryapranat $H$, van den Brand $M$, Serruys $P W$. Immediate and long term results of percutaneous coronary angioplasty in patients aged 70 and over. Br Heart $71992 ; 67: 138-43$.

29 Maiello L, Colombo A, Gianrossi R, Thomas J, Finci L. Percutaneous transluminal coronary angioplasty in patients aged 70 years and older: immediate and longterm results. Int $f$ Cardiol 1992;36:1-8.

30 Kern MJ, Deligonul U, Galan K, et al. Percutaneous transluminal coronary angioplasty in octogenarians. $\mathrm{Am}$ Cardiol 1988;61:457-8.

31 Rich JJ, Crispino CM, Saporito JJ, Domat I, Cooper WM. Percutaneous transluminal coronary angioplasty in patients 80 years of age and older. Am $\mathcal{F}$ Cardiol 1990; 65:675-6.

32 Rizo-Patron C, Hamad N, Paulus R, Garcia J, Beard E. Percutaneous transluminal coronary angioplasty in octogenarians with unstable coronary syndromes. $\mathrm{Am}$ Cardiol 1990;66:857-8.

33 Jeroudi MO, Kleiman NS, Minor ST, et al. Percutaneous transluminal coronary angioplasty in octogenarians. $A n n$ Intern Med 1990;113:423-8.

34 Santana JO, Haft JI, LaMarche NS, Goldstein JE. Coronary angioplasty in patients eighty years of age or older. Am Heart ₹ 1992;124:13-8.

35 Deligonul U, Vandormael MG, Kern MJ, Zelman R, Galan K, Chaitman BR. Coronary angioplasty: a therapeutic option for symptomatic patients with two and three vessel coronary disease. $₹ \mathrm{Am}$ Coll Cardiol 1988; 11:1173-9.

36 Bell MR, Bailey KR, Reeder GS, Lapeyre AC, Holmes DR. Percutaneous transluminal angioplasty in patients with multivessel coronary disease: how important is with multivessel coronary disease: how important is vival? ₹ Am Coll Cardiol 1990;16:553-62.

37 Stevens T, Kahn JK, McCallister BD, et al. Safety and efficacy of percutaneous transluminal coronary angioplasty in patients with left ventricular dysfunction. $A m \quad \mathcal{F}$ Cardiol 1991;68:313-9.

38 Serota H, Deligonul U, Lee WH, et al. Predictors of cardiac survival after percutaneous transluminal coronar angioplasty in patients with severe left ventricular dysfunction. Am $\mathcal{F}$ Cardiol 1991;67:367-72.

39 Topol EJ. Emerging strategies for failed percutaneous transluminal coronary angioplasty. Am $f$ Cardiol 1989; 63:249-50.

40 Lee T, Hartzler GO, Rutherford BD, McConahay DR. Removal of an occlusive coronary dissection flap usin an atherectomy catheter. Cathet Cardiovasc Diagn 1990; 20:185-8.

41 Sigwart U, Puel J, Mirkovitch V, Joffre F, Kappenberge L. Intravascular stents to prevent occlusion and restenosis after transluminal angioplasty. $N$ Engl $f \mathrm{Med}$ 1987;316:701-16.

42 Kahn JK, Rutherford BD, McConahay DR, Johnson WI Giorgi LV, Hartzler GO. Supported "high-risk" coronary angioplasty using intraaortic balloon pump counnary angioplasty using intraaortic balloon pum

43 Vogel RA, Shawl F, Tommaso C, et al. Initial report of the National Registry of elective cardiopulmonary bypass 
supported coronary angioplasty. F Am Coll Cardiol 1990;15:23-9.

44 Tsai TP, Chaux A Matloff JM, et al. Analyses of mortality, morbidity and survivors after coronary artery bypass surgery in patients age 80

45 Darling GE, Mullany CJ, Schaff HV, Orszulak TA. Early survival and functional results of coronary artery bypass in octogenarians [abstract]. Circulation 1989;80(suppl II): II-626.

46 Jones EL, Craver JM, Guyton RA, Bone DK, Hatcher CR, Riechwald N. Importance of complete revascularization in performance of the coronary bypass operation. $\mathrm{Am} \mathcal{F}$ Cardiol 1983;51:7-12.

47 Lawrie GM, Morris GC, Silvers A, et al. The influence of residual disease after coronary artery bypass on the 5-year survival rate of 1274 men with coronary artery disease. Circulation 1982;66:717-23.

48 Lavee J, Rath S, Tran-Quang-Hoe. Does complete revascularization by the conventional method truly provide the best possible results? Analysis of results and comparison with revascularization of infarct-prone segments (systematic segmental myocardial revascularizaments (systematic segmental myocardial revasculariza-
tion): the Sheba Study. $\mathcal{F}$ Thorac Cardiovasc Surg tion): the Sheb

49 Finci L, Meier B, De Bruyne R, Steffenino G, Divernois J, Rutishauser W. Angiographic follow-up after multivessel percutaneous transluminal coronary angioplasty. $\mathrm{Am} \mathcal{F}$ Cardiol 1987;60:467-70.

50 Faxon DP, Ghalilli $\mathrm{K}$, Jacobs AK, et al. The degree of revascularization and outcome after multivessel coronary angioplasty. Am Heart f 1992;123:854-9. 